\title{
MANAJEMEN SISTEM PENERANGAN DENGAN KENDALI ON/OFF RELAY PADA GEDUNG MENGGUNAKAN MIKROKONTROLLER DAN METODE POLLING
}

\author{
Duta Widhya Sasmojo ${ }^{a}$, Agung Saputra, ${ }^{\text {b) }}$, Gunady Haryanto ${ }^{c}$, \\ Sri Rezeki Candra Nursari ${ }^{\mathrm{d})}$, Wisnu Broto ${ }^{\mathrm{e})}$, Bambang Riono Arsad ${ }^{\mathrm{f}}$, \\ Fauzie Busalim $^{\mathrm{g}}$, M. Yaser ${ }^{\mathrm{h}}$ )
}

Prodi Teknik Elektro Fakultas Teknik Univ. Pancasila

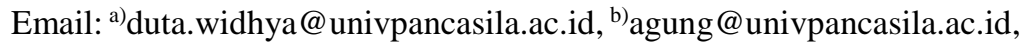
c) gunady.haryanto@univpancasila.ac.id, ${ }^{\mathrm{d})}$ sri.rezeki.candra.n@univpancasila.ac.id,

e)wisnubroto@univpancasila.ac.id, ${ }^{\text {f) }}$ bambang.riono@univpancasila.ac.id,

g)fauzie.busalim@univpancasila.ac.id, h) muhammadyaser@univpancasila.ac.id
\end{abstract}

\begin{abstract}
Abstrak
Penghematan energi listrik dibutuhkan, mengingat saat ini energi baru terbarukan belum banyak berkembang dan masih mengandalkan energi berbasis fosil yang semakin hari semakin langka. Salah satu komponen yang mengkonsumsi energi listrik adalah penggunaan penerangan. Pada umumnya gedung-gedung sebagai pusat kegiatan saat ini masih mengandalkan swith on-off yang terpasang pada dinding untuk mematikan/menghidupkan penerangan dan dibutuhkan operator untuk mengoperasikannya. Faktor manusia dan area yang luas dalam gedung menjadikan tingkat efisiensi penggunaan energi listrik sangat tergantung dari operator tersebut. Ketidak efisienan penggunaan energi listrik untuk penerangan lampu didapat ketika penerangan menyala pada waktu yang tidak tepat, misal pada siang hari, atau area yang seharusnya dimatikan. Sistem kendali on/off terpusat merupakan salah satu solusi untuk mengoptimalisasi penggunaan energi listrik bagi penerangan gedung dengan mengganti kendali on/off switch yang terpasang di dinding dengan penggunaan relay yang dikendalikan oleh mikrokontroler terpusat. Dalam penelitian ini penggunaan relay dikendalikan oleh mikrokontroler Arduino yang bekerja mendapat perintah dengan membaca data secara periodik ke server yang dihubungkan dengan internet. Pengguna dapat mematikan atau menyalakan penerangan lampu dengan mengakses web server yang telah terprogram dan menyimpan status relay tersebut dalam sebuat basis data mysql. Hasil penelitian ini mendapatkan sebuah sistem kendali on/off relay yang bekerja dibalik NAT dengan menggunakan IP lokal yang dapat mengakses ke server di internet. Pembacaan status relay dilakukan secara polling secara periodik 10 detik sekali untuk mengetahui status akhir. Pemasangan peralatan dilakukan dengan cara paralel dengan on/off switch yang sudah terpasang di dinding agar tidak banyak merombak struktur kelistrikan yang ada dan antisipasi cadangan bila sistem kendali on/off otomatis mengalami kegagalan.
\end{abstract}

Kata-kata kunci: Relay, Mikrokontroller, Energi Listrik, Polling, Sistem Kendali On/Off

\begin{abstract}
Electricity energy savings are needed, considering that currently new renewable energy has not developed much and still relies on fossil-based energy which is increasingly scarce. One component that consumes electrical energy is the use of lighting. In general, buildings as a center of activity currently
\end{abstract}


still rely on switch on-off installed on the wall to turn off / turn on lighting and operators need to operate it. Human factors and large areas in the building make the level of efficiency in the use of electrical energy highly dependent on the operator. Inefficient use of electrical energy for lighting lamps is obtained when lighting lights up at an incorrect time, for example during the day, or an area that should be turned off. Centralized on / off control system is one solution to optimize the use of electrical energy for building lighting by replacing wall-mounted on / off switches with the use of a relay controlled by a centralized microcontroller. In this study the use of relays is controlled by an Arduino microcontroller that works by getting orders by reading data periodically to a server connected to the internet. Users can turn off or turn on lighting by accessing a pre-programmed web server and store the status of the relay in a MySQL database. The results of this study get an on / off relay control system that works behind NAT by using a local IP that can access the server on the internet. The relay status readings are carried out in polls and periodically 10 seconds to find out the final status. Installation of equipment is carried out in a parallel with the on / off switch installed on the wall so it won't need to overhaul the existing electrical structure and anticipate reserves if the automatic on / off control system fails.

Keywords: Relay, Micro controller, Electricity Energy, Polling, On/Off Control System

\section{PENDAHULUAN}

Penghematan energi listrik merupakan isu yang strategis, mengingat sebagian besar energi listrik yang dikonsumsi oleh objek-objek tersebut dihasilkan dari pembangkit listrik yang masih menggunakan bahan bakar fosil dan juga keterbatasan pembangkit untuk memenuhi kebutuhan konsumen. Salah satu komponen yang mengkonsumsi energi listrik terbesar pada objek-objek tersebut di atas adalah penerangan pada gedung. Pengaturan pengoperasian penerangan pada gedung kebanyakan dilakukan secara manual menggunakan switch on-off . Sistem tersebut tidaklah efektif dan efisien karena kendali bergantung kepada seorang atau beberapa operator untuk menghidupmatikannya.

Kontrol otomatik telah memegang peranan dalam perkembangan ilmu pengetahuan dan teknologi. Dimana kontrol otomatik menjadi bagian yang penting dan terpadu untuk mengontrol tekanan, kecepatan suhu dan aliran dalam proses (Ogata, K., 1996).

Kebutuhan akan kontrol listrik yang dapat diprogram On-Off sesuai dengan kebutuhan pengguna adalah suatu masalah. pemanfaatan dari mikrokontroller untuk fungsi tersebut dapat di memungkinkan. Sistem kontrol On-Off adalah sistem kontrol yang bisa diaplikasikan pada hampir semua peralatan listrik yang mempunyai dua kondisi yaitu ON dan OFF (Hamdan dan Winardi, 2012).

Pada suatu gedung perkuliahan saat ini dimana dalam menghidup-matikan penerangan masih menggunakan sistem kontak On-Off secara langsung oleh operator, sehingga tidak efektif dan efisiennya penggunaan penerangan yang cenderung faktor kelalaian pengontrolan yang mengakibatkan pemborosan energi listrik . Pengontrolan penerangan tidak berjalan dengan baik hal ini dikarenakan beberapa sebab :

a. Setiap lampu dihidup-matikan dengan switch On-Off masing-masing

b. Di dalam ruang beberapa lampu digabung dalam satu Switch On-Off

c. Setiap ruang kelas-kelas memiliki switch On-Off masing-masing.

d. Belum adanya kesadaran bagi civitas dalam ikut pengontrolan penerangan dan keterbatasan operator dalam pengontrolan penerangan penerangan disekitarnya.

Penelitian ini bermaksud melakukan analisis penghematan energi listrik penerangan melalui sistem kendali On-Off menggunakan mikrokontroler yang dikendalikan melalui konsep Internet Of Things (IOT). Untuk memudahkan didalam pengendalian dan pengontrolan diperlukan pengalamatan untuk masing-masing lampu dan pembagi dalam blok penerangan agar pengaturan penggunaan penerangan dapat lebih termonitor secara optimal dan terkendali dalam satu pusat monitoring. Pengendalian sistem di desain dengan perlakukan melalui jaringan komputer (LAN) yang telah ada sebelumnya agar mengoptimalkan penggunaan peralatan yang telah tersedia. Tujuan dari penelitian ini adalah membuat prototype unit sistem pengontrol dan pengendalian switch on/off untuk 
penerangan gedung menggunakan mikrokontroller dengan metode polling berbasis IOT agar penerangan pada gedung dapat dikendalikan lewat jaringan internet.

\section{METODOLOGI}

Didalam penyelesaian permasalahan tersebut diatas diperlukan suatu metode yang dipergunakan peneliti untuk melakukan solusi. Metode tersebut harus berkaitan dengan penggunaan switch On-Off penerangan lampu, karena ingin melakukan optimalisasi peralatan yang ada berikut penggunaan jaringan LAN. Metode yang dilakukan peneliti adalah pengaturan titik-titik lampu dengan pemberian alamat untuk masing-masing titik lampu sesuai posisinya. Dan pemberian alamat digunakan dengan sistem berjenjang, yaitu pengalamatan perkelompok besar kemudian pengalamatan perkelompok dibawah/ sub-nya. Selanjutnya dengan telah membentuk titik-titik switch ke dalam alamat-alamat yang bertujuan untuk memudahkan dalam pengendalian. Metode polling diterapkan pada penelitian ini untuk proses pengontrolan pada posisi switch On-Off yang ada.

Untuk memperjelas metode dapat ditunjukkan dengan blok diagram di bawah ini :

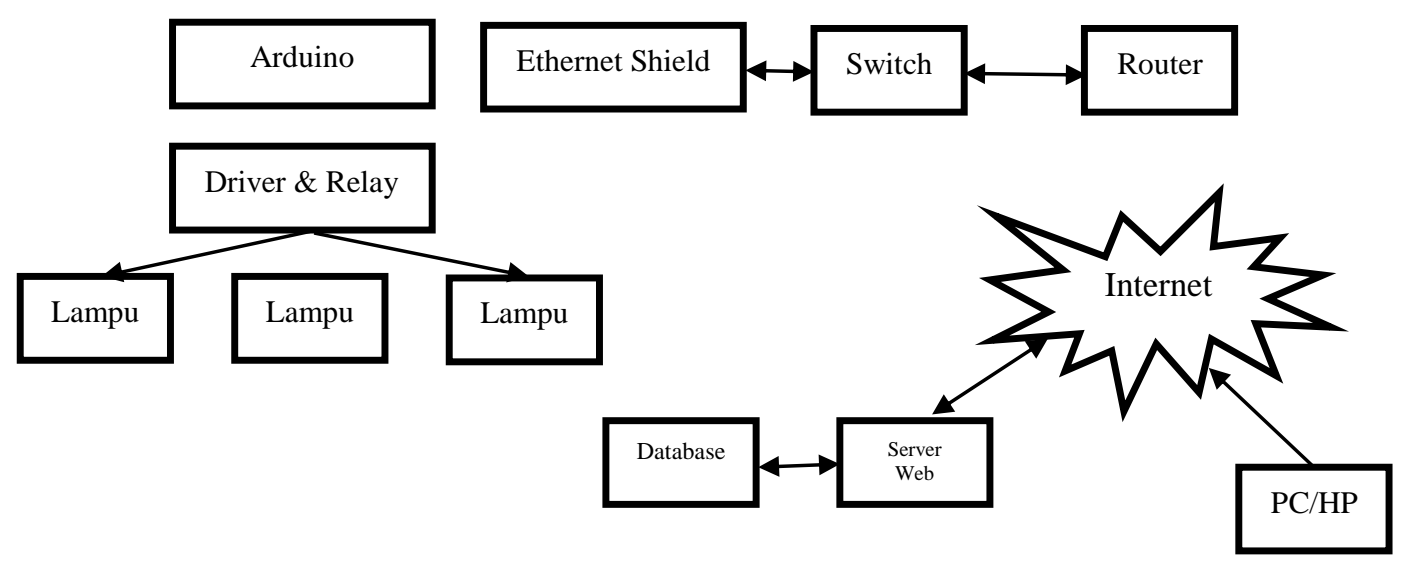

GAMBAR 1. Diagram sistem kendali on/off berbasis IOT

Flowchart kerja sistem secara kesuluruhan dapat ditunjukkan sebagai berikut :

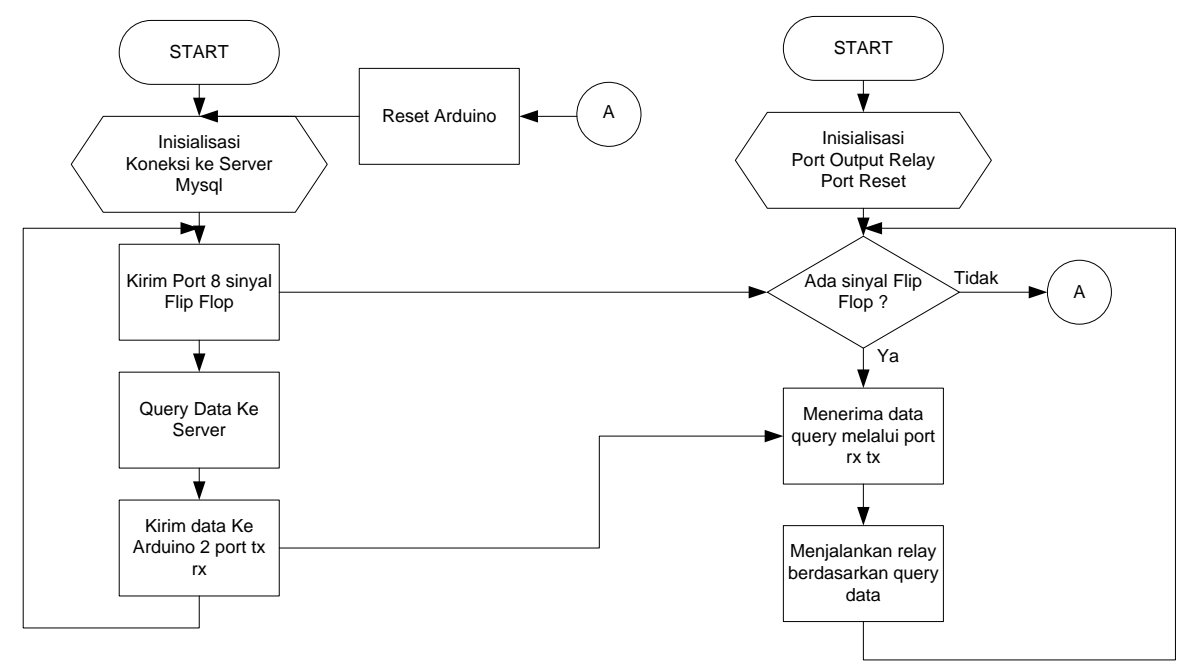

GAMBAR 2. Flowchart sistem keseluruhan 
Algoritma untuk metode polling pada sistem ini dapat ditunjukkan sebagai berikut :

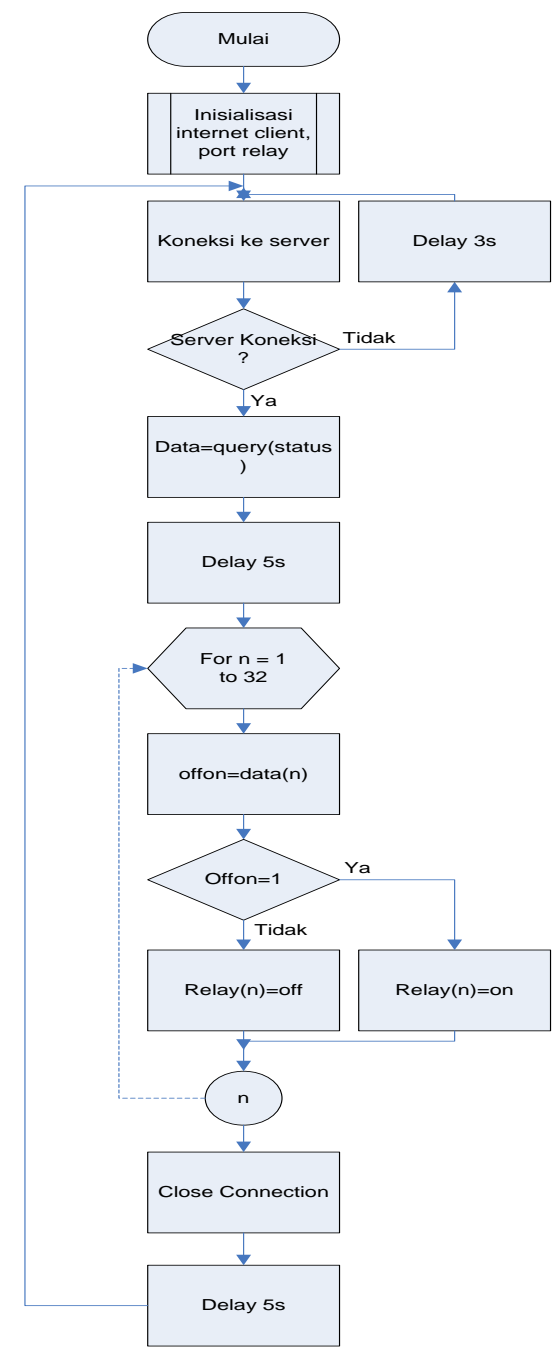

GAMBAR 1. Algoritma metode polling pada sistem
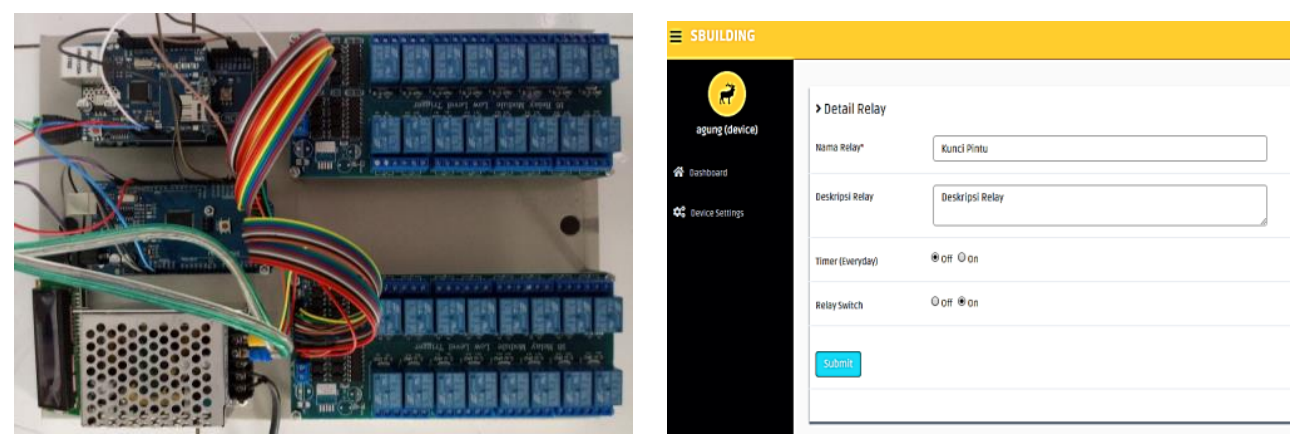

GAMBAR 2. a) Rangkaian pengendali peralatan listrik, b) Tampilan konfigurasi relay 


\section{HASIL DAN PEMBAHASAN}

Guna mendapatkan hasil yang diinginkan peralatan yang sesuai dengan tujuan penelitian. Saat ini telah diuji dalam bentuk model prototype yang dibangun berupa bentuk ruang-ruang sederhana dengan pengendalian 7 lampu secara elektronik.

Pengujian dilakukan untuk mengetahui kehandalan sistem dalam mengontrol kendali on/off dengan mengetahui lamanya respon rata-rata dan lamanya sistem memulihkan kembali koneksi ke server setelah adanya gangguan koneksi antar sistem dan server.

Pada pengujian waktu respon setelah merubah status on-off di aplikasi web terlihat pada TABEL 1 berikut.

TABEL 1 . Pengujian waktu respon

\begin{tabular}{cccc}
\hline No Pengujian & Mulai Aksi [Waktu] & Reaksi Status [Waktu] & Lama Respon [Detik] \\
\hline 1 & 09.00 .00 & 09.00 .11 & 11 \\
\hline 2 & 09.01 .00 & 09.01 .10 & 10 \\
\hline 3 & 09.02 .00 & 09.02 .12 & 12 \\
\hline 4 & 09.03 .00 & 09.03 .10 & 11 \\
\hline 5 & 09.04 .00 & 09.04 .11 & 13 \\
\hline 6 & 09.05 .00 & 09.05 .13 & 11 \\
\hline 7 & 09.06 .00 & 09.06 .11 & 10 \\
\hline 8 & 09.07 .00 & 09.07 .10 & 11 \\
\hline 9 & 09.08 .00 & 09.08 .10 & \\
\hline 10 & 09.09 .00 & 09.09 .11 &
\end{tabular}

Hasil pengujian waktu respon dilakukan pengujian 10 kali menunjukan rata-rata respon sistem setelah di lakukan aksi on-off di aplikasi web akan berpengaruh pada sistem sekitar 10,9 detik. Beragam nya waktu respon dikarenakan salah satunya pengatuh koneksi yang tidak stabil antara pengguna ke server dan menuju ke sistem.

Pada pengujian yang kedua, dilakukan skenario dengan pemutusan jaringan internet antara server dan sistem kendali. Gangguan ini guna mengetahui seberapa cepat sistem dapat pulih kembali ke sedia kala ketika koneksi telah normal kembali. Hasil percobaan dapat dilihat di TABEL 2 berikut ini.

TABEL 2. Pengujain waktu pemulihan sistem terhadap gangguan koneksi internet

\begin{tabular}{cccc} 
No Pengujian & $\begin{array}{c}\text { Mulai Pemulihan } \\
\text { [Waktu] }\end{array}$ & $\begin{array}{r}\text { Respon Penyambungan } \\
\text { [Waktu] }\end{array}$ & $\begin{array}{c}\text { Lama Pemulihan } \\
\text { [Detik] }\end{array}$ \\
\hline 1 & 10.00 .00 & 10.00 .15 & 15 \\
\hline 2 & 10.05 .00 & 10.05 .14 & 14 \\
\hline 3 & 10.10 .00 & 10.10 .13 & 13 \\
\hline 4 & 10.15 .00 & 10.15 .16 & 14 \\
\hline 5 & 10.20 .00 & 10.20 .14 & 15 \\
\hline 6 & 10.25 .00 & 10.25 .15 & 13 \\
\hline 7 & 10.30 .00 & 10.30 .14 & 15 \\
\hline 8 & 10.35 .00 & 10.35 .13 & 13 \\
\hline 9 & 10.40 .00 & 10.40 .15 & \\
\hline 10 & 10.45 .00 & 10.45 .13 & \\
\hline
\end{tabular}

Hasil pengujian waktu respon pemulihan dilakukan pengujian 10 kali menunjukan rata-rata waktu sistem kendali normal kesedia kala sekitar 14,2 detik. Beragam nya waktu pemulihan dikarenakan salah satunya pengaruh koneksi yang tidak stabil antara pengguna ke server dan menuju ke sistem. 


\section{SIMPULAN}

Pada penelitian ini, dapat disimpulkan sementara sebagai berikut :

1. Pengendalian On-Off pada lampu atau peralatan listrik telah dapat diperoleh sesuai dengan rencana kerja

2. Waktu respon antara kondisi on-off di aplikasi dengan sistem kendali rata-rata 10,9 detik dengan dipengaruhi oleh koneksi jaringan internet.

3. Pada waktu pengujian pemulihan kembali ketika terjadi putus koneksi, rata-rata waktu yang dibutuhkan untuk normal kembali setelah koneksi internet pulih sekitar 14,2 detik.

4. Telah dirancang aplikasi pengedali bagi pengguna berbasis web dan telah diuji penggunaannya dan berjalan dengan baik.

\section{REFERENSI}

[1] Kementrian Ketenagaan. (2005). Peralatan Energi Listrik: Pencahayaan. India: Biro Efisiensi Energi.

[2] Irianto, C. G. (2006). Studi Optimasi Sistem Pencahayaan Ruang Kuliah Dengan Memanfaatkan Cahaya Alam. JETri, 1.

[3] Ridwan. Pengantar Sistem Tata Udara.

[4] Arduino Home. (2018, 10 01). Diambil kembali dari Arduino: https://www.arduino.cc/

[5] Internet untuk Segala. (2018, 08 15). Diambil kembali dari Wikipedia: https://id.wikipedia.org/wiki/Internet_untuk_Segala

[6] 199 iot Projects. (2018, 09 02). Diambil kembali dari Arduino Project HUB: https://create.arduino.cc/projecthub/projects/tags/iot

[7] Artanto. 2012.APLIKASI MIKROKONTROLER ATMega8535 dan ATMega16. Yogyakarta: ANDI.

[8] Banzi, Massimo. 2008. Getting Started with Arduino, First Edition. Sebastopol: Reilly.

[9] Djuandi. 2011. Pengukur Suhu Badan Berbasis Mikrokontroler AVR 8535 Dengan Tampilan LCD. Tugas Akhir, Univerisitas Narotama Surabaya.

[10] Hamdani, Mohammad. 2010. Pengendali Kecepatan Putaran Motor DC Terhadap Perubahan Temperatur Dengan Sistem Modulasi Lebar Pulsa. Depok: Universitas Indonesia.

[11] Lucky Yuditia Putra, 2013.Modul Latih Mikrokontroler Arduino Uno Untuk Mengontrol Suhu Ruangan Dengan Menggunakan Sensor Suhu, Kipas dan Liquid Crystal Display. Skripsi. Jurusan Teknik Elektro, Fakultas Teknik Universitas Mercu Buana.

[12] Lukman Hakim, 2010. Perancangan Remote Control untuk Mengendalikan Kipas Angin berbasis Mikrokontroler AT90s2313 dan ATMEGA8. Tugas Akhir. Universitas Negeri Malang.

[13] McRoberts, Mike. 2009. Ardunio Starter Kit Manual - A Complete Beginner Guide to the Arduino. UK: Earthshine Design.

[14] Putu Rusdi Ariawan. 2009. Sistem Pengaturan On/Off dengan Menggunakan Sensor Suhu. Tugas Akhir. Teknik Elektro. Universitas Udiyana.

[15] Robertson, Christopher R. 2008. Fundamental Electrical and Electronic Principles, Third Edition. Oxford: Newnes.

[16] Samuel Aji Sena. 2013. Perancangan dan pembuatan Application Programming Interfaceserver untuk arduino, Skripsi, Jurusan Teknik Elektro, Fakultas Universitas Brawijaya. 
[17] Widianto, 2012, From Mewbie To Advanced, Mudahnya Membuat Aplikasi Android. Yogyakarta. Andi.

[18] Arduino, 2016, Arduino Uno Board, https://www.arduino.cc/en/Main/ArduinoBoardUno, diakses 11 Februari 2016.

[19] Daely, P. T., 2015, Pemantau Sinyal Vital Pasien Nirkabel Menggunakan Protokol ZigBee Pada Platform E-Health, Skripsi, Jurusan Teknik Elektro FTE Universitas Telkom, Bandung. 
